\title{
Evaluation of technological characteristics of Crimean native grape variety 'Shabash' for brandy production
}

\author{
Olga Chursina ${ }^{1,}{ }^{*}$, Viktor Zagorouiko ${ }^{1}$, Ludmila Legasheva ${ }^{1}$, Alina Martynovskaya ${ }^{1}$, Marina \\ Prostak $^{2}$ \\ ${ }^{1}$ All-Russian National Research Institute of Viticulture and Winemaking "Magarach" of the RAS, 31 \\ Kirova Str., 298600, Yalta, Republic of Crimea, Russia \\ ${ }^{2}$ Limited liability company "Cognac House "Koktebel”, 19, Makedonsky Str., 298187, Shchebetovka \\ village, Feodosiya, Republic of Crimea, Russia
}

\begin{abstract}
The article presents the results of study of physicochemical and biochemical parameters of the Crimean native grape variety 'Shabash' and their influence on the composition of aroma-forming complex of wine materials and young brandy distillates. The phenolic complex of grapes was characterized by higher parameters of technological stock of phenolic substances of grapes, the ability of grapes to give off phenolic substances in grape-crushing, the weight concentration of phenolic substances of the must after maceration. The resulting wine materials also differed by a high content of phenolic substances and the degree of their oxidation. Main features of the composition of the base aroma-forming components of brandy wine materials and distillates, characterized by an increased content of higher alcohols and a reduced content of medium-chain esters, were revealed. A close connection of a number of parameters of grapes with the composition of the volatile components of wine materials and distillates was established. It is shown that the native variety possesses high potential for the fine brandy production using the technology of single variety. The studies conducted are the stage of the scientifically grounded formation of the base of row materials for brandy production in the Russian Federation.
\end{abstract}

\section{Introduction}

An important role in solving the problem of import substitution in brandy production belongs to the creation of a high-quality base of raw materials on the ground of the best grape varieties of different origin (alien, selected, native), providing the production of highquality and competitive goods.

A promising direction in the varietal structuring of the viticulture of Crimea is the expansion of plantings of native (autochthonous) grape varieties, allowing to produce the original organoleptic output thanks to the unique conditions of grapes habitat.

\footnotetext{
*Corresponding author: olal45@mail.ru
} 
Despite the fact that about 80 autochthonous grape varieties grow in the Crimea, no more than 10 are commercially used in winemaking, mainly for the production of liqueur wines.

Grape variety 'Shabash' belongs to the group of eastern table and wine varieties of late ripening and is characterized by high yield capacity, reaching $150 \mathrm{c} /$ ha (an average of 70 $80 \mathrm{c} / \mathrm{ha}$ ). It is cultivated in Crimea on the area of about 2 thousand hectares, which is $7,8 \%$ of the total area of vineyards. The grape variety is mainly distributed in the eastern part of the South Coast zone of the peninsula, partly in the western piedmont-seaside region. Currently, grapes are used mainly for the production of dry and liquor wines, and for fresh consumption.

Main role in shaping the quality of brandy products is played by a complex of aromaforming substances, consisting of the compounds of various classes (esters, aldehydes, alcohols, volatile acids, etc.). Level of the content depends on a variety of agro-ecological and technological factors, playing a key role in the varietal features of grapes, its biological and technological characteristics. The creation of a single-variety technology that fully reaches the grape biopotential, necessitates a comprehensive study of its varietal characteristics and their influence on the quality of brandy products [1-16].

The aim of the research was to study the influence of the main physicochemical and biochemical parameters of the Crimean native grape variety 'Shabash' on the composition of the aroma-forming complex of wine materials and young brandy distillates.

\section{Materials and Methods}

The research materials were: native grape variety 'Shabash' of 2015-2018 crop years, growing in two geographical zones of Republic of Crimea: Piedmont (village Vilino of Bakhchisaray district) and Eastern (town settlement Koktebel, Feodosiya); brandy wine materials obtained in the conditions of microvinification according to standard technology (grape crushing with destemming, must separation, must settling for 12 hours at a temperature of $10-12{ }^{\circ} \mathrm{C}$, must fermentation using pure yeast cultures from the collection of microorganisms of winemaking of the FSBSI All-Russian National Research Institute of Viticulture and Winemaking "Magarach" of the RAS); young brandy distillates produced on a Charante bench-scale distillation plant. There were prepared 26 batches of brandy wine materials and young brandy distillates in total. The variety 'Rkatsiteli' was used as a control.

The analysis of grapes was carried out according to the "Methodology of assessing grape varieties according to physicochemical and biochemical parameters" including, amongst the main parameters of carbohydrate-acidic composition, the indices of technological stock of phenolic substances in grapes (TSPhS), mass concentration of phenolic components of the must after grape-crushing (PhSinit) and after pomace infusion (PhSpi), macerating ability of grapes (PhSmac), ability of grapes to oxidize ( $\mathrm{PhSox})$ and to release phenolic substances $(\mathrm{PhSr})$, as well as monophenolmonooxygenase (MPhMO) and specific enzymatic activity of the must straight after grapes crushing. The analysis of chemical composition of wine materials was carried out by generally accepted methods according to "Compendium of international methods of analysis of wines and musts". The aroma-forming complex of wine materials and distillates was provided by the method of gas chromatographic separation of the components on chromatograph Agilent Technology 6890 with mass spectrometric detector. The mass concentration of organic acids in must and wine materials was determined by HPLC (Shimadzu LC20AD Prominence chromatograph, Japan). Organoleptic evaluation of wine materials and distillates was carried out with the participation of the tasting commission of the FSBSI All-Russian National Research Institute of Viticulture and Winemaking "Magarach" of the RAS. 
Microbiologically resistant wine materials with the quality rating not less than satisfactory, were used in the research. The results of the studies were classified, processed by methods of mathematical statistics using computer technology software.

\section{Discussion of the results}

Studies of the physicochemical and biochemical parameters of native grape variety 'Shabash' showed a number of distinctive features that must be taken into account in the production of brandy distillates, especially using the technology of single variety. First of all it concerns the technological parameters of the composition of the acid and phenolic complexes and the oxidase system of technically ripened grapes.

A distinctive feature of the native variety in comparison with 'Rkatsiteli' grape variety, basic for brandy production, was the low level of titratable acids, varied in the range of 3,3$5,6 \mathrm{~g} / \mathrm{dm} 3$ (4,4 g/dm3 on average), which led to the increased $\mathrm{pH}$ values 3,1-3,5 (3,3 on average). For 'Rkatsiteli' grape variety these indices amounted 5,0-6,9 g/dm3 (6,2 g/dm3 on average) and $\mathrm{pH} 3,0-3,4$ (3,2 on average). Tartaric and malic acids prevailed in the composition of organic acids of the native variety, but their total share was lower (70 \% on average) than in 'Rkatsiteli' variety (91\% on average) (Figure 1). Taking into consideration the high liability of low-acid wine materials to microbiological spoiling and oxidation during the storage, the mass concentration of titratable acids in brandy wine materials should be at least $8,0 \mathrm{~g} / \mathrm{dm} 3$ according to the recommendations of a number of authors.

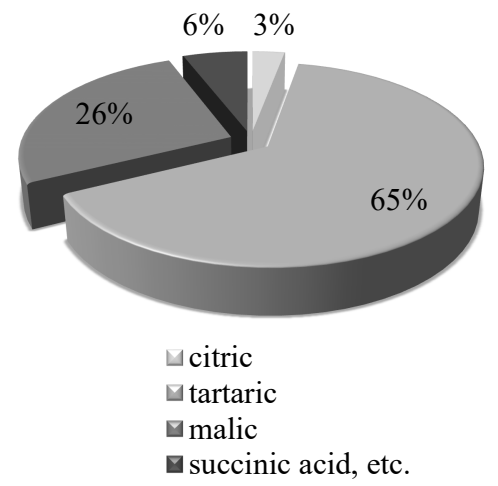

a)'Shabash'

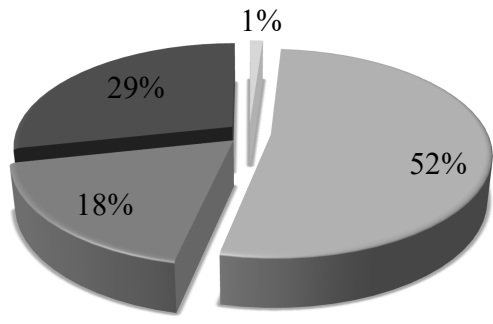

$\square$ citric

$\square$ tartaric

$\square$ malic

a succinic acid, etc.

b)'Rkatsiteli'

Fig. 1. Mass concentration of organic acids $\left(\mathrm{g} / \mathrm{dm}^{3}\right)$ of 'Shabash' grape variety (a) and 'Rkatsiteli (b).

The phenolic complex of grapes was characterized by a higher level of technological stock of grape phenolic substances (TSPhS) (by $8 \%$ ), the ability of grapes to give off the phenolic substances when crushing grapes (by $12 \%$ ), and the mass concentration of phenolic substances in must after pomace infusion (PhSpi) (by 67\%), the mass concentration of phenolic components of must after grape-crushing (PhSinit) (by $22 \%)$. At the same time, lower monophenolmonooxygenase activity (MPhMO) of the must was observed (by $45 \%$ ) (Figure 2). 


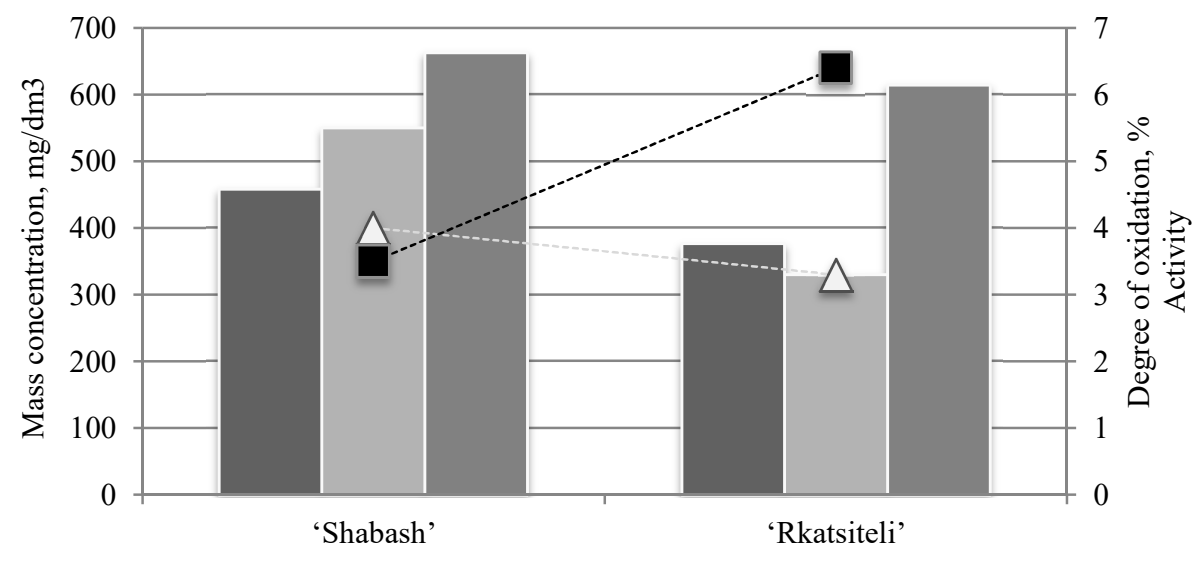

Grape variety

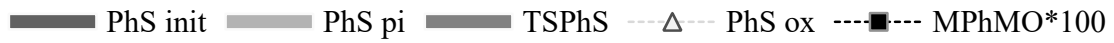

Fig. 2. Physicochemical and biochemical parameters of 'Shabash' and 'Rkatsiteli' grape varieties.

Phenolic substances are the main substrate for oxidases that easily involve in redox processes with the formation of oxidation products, which can have a negative impact on the quality of the finished product. It makes necessary to limit its content in brandy wine materials to the level of $200-250 \mathrm{mg} / \mathrm{dm} 3$, according to data of the number of authors [18, 19]. After the studies conducted, wine materials produced from 'Shabash' variety were characterized by a high content of phenolic substances $255-462 \mathrm{mg} / \mathrm{dm} 3(330 \mathrm{mg} / \mathrm{dm} 3$ on average) exceeding the recommended level, and by oxidation degree - 0,29$0,54 \mathrm{mVdm} 3 / \mathrm{mg}(0,40 \mathrm{mVdm} 3 / \mathrm{mg}$ on average $)$.

Sparing modes, reducing the contact of the must with the solid fractions of the pulp, antioxidant protection, must fining should be used to ensure the required level of parameters in grape processing.

The analysis of aroma-forming components of brandy wine materials of the studied variety showed a higher content of volatile components (by $43 \%$ ) including volatile acids $(1,7$ times) and higher alcohols (20\%) compared to the control (Figure 3$)$.

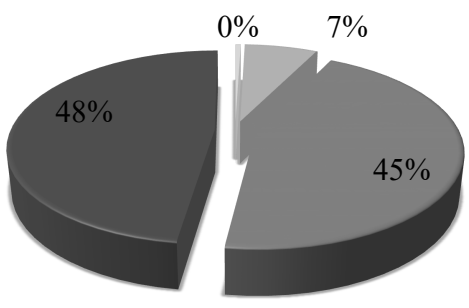

$\square$ aldehydes $\square$ medium-chain esters $\square$ higher alcohols Qvolatile acids

a) 'Shabash'

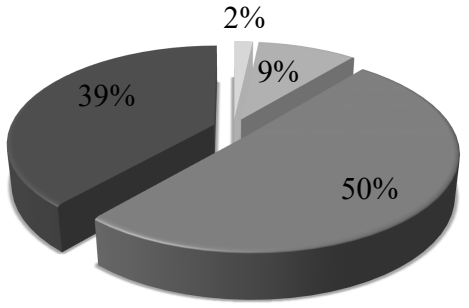

$\triangle$ aldehydes $\square$ medium-chain esters $\square$ higher alcohols Qvolatile acids

b) 'Rkatsiteli'

Fig. 3. Composition of aroma-forming elements of wine materials of 'Shabash'(a) and 'Rkatsiteli'(b) grape varieties. 
The content composition of wine materials showed a higher level of mass concentration of diethyl succinate (by $20 \%$ ), $\beta$-phenylethyl alcohol (by $22 \%$ ), isoamyl alcohol (by $35 \%$ ), ethyl acetate (by $9 \%$ ), hexanol (1,9 times) and lower content of the component of the enanthic ester: ethylcaprylate (by $28 \%$ ).

By the ratio of the main components of aroma-forming structure - medium-chain esters to higher alcohols, which determined the quality of brandy production, native wine materials were slightly inferior to wine materials of 'Rkatsiteli', with the values 0,15 and 0,18 , respectively.

According to the organoleptic characteristics, wine materials made of 'Shabash' variety had following varietal features: the aroma of a spicy-fruit direction, with dry herbal and light honey notes, full-bodied harmonious flavor.

Mathematical processing of the data revealed a close relationship of the physicochemical and biochemical parameters of grapes with the composition of the volatile elements of wine materials. It was established that the increase in $\mathrm{pH}$ is closely correlated with the mass concentration of the sum of volatile components, higher alcohols and volatile acids in wine material; an increase in the mass concentration of sugars in grapes contributes to a decrease in the proportion of higher alcohols in the sum of volatile components and an increase in the content of medium-chain esters, and, in compliance, the parameter of the ratio of medium-chain esters mass concentration to higher alcohols.

Fractionating of volatile impurities during the distillation of wine materials leads to their redistribution: in young brandy distillates the content of volatile acids significantly decreases as a result of the extraction of the afterrun, and the concentration of higher alcohols in the sum of volatile impurities increases, which leads to a decrease in the proportion of medium-chain esters and their ratio with higher alcohols. Improving the quality of brandy distillates is promoted by technological methods aimed at reducing the proportion of higher alcohols and increasing the content of medium-chain esters.

Young brandy distillates made of 'Shabash' grape variety had following by a higher content of volatile components than 'Rkatsiteli' grape variety $(386,9 \mathrm{mg} / 100 \mathrm{~cm} 3 \mathrm{a}$.a. and $340,0 \mathrm{mg} / 100 \mathrm{~cm} 3$ a.a., respectively) which creates a good base for their long exposure and the formation of high quality of the cognac (Figure 4). The analysis of aroma-forming components of young brandy distillates of the studied variety showed a higher content of higher alcohols (by $16 \%$ on average) including $\beta$-phenylethyl alcohol (by $73 \%$ on average) and components of the enanthic ester (by $17 \%$ on average), and lower content of the component of the medium-chain esters and aldehydes.

According to the organoleptic characteristics, young brandy distillates made of 'Shabash' variety had following the aroma of a spicy-fruit direction, with light honey and nut notes, full-bodied flavor.

Despite the multistaging of the process of obtaining young brandy distillates, the influence of grape indices on the composition of volatile impurities of brandy distillates was mathematically confirmed. It was also established that a decrease in the content of isoamyl alcohol and an increase in the ratio of the mass concentration of medium-chain esters to higher alcohols in young brandy distillates are closely connected with an increase in the sugar content in grapes; an increase in the tasting score of brandy distillates correlates with an increase in the content of medium-chain esters. 


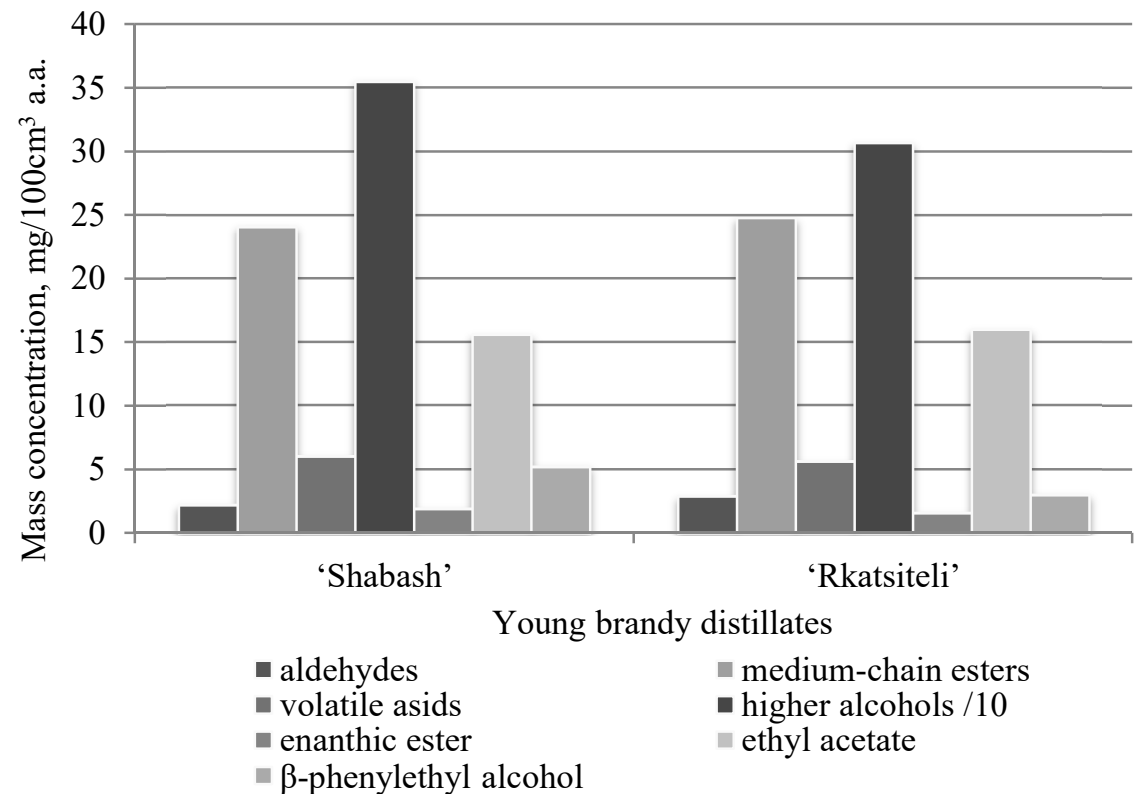

Fig. 4. Mass concentration of volatile impurities of brandy distillates of 'Shabash' and 'Rkatsiteli' grape varieties.

Thus, the study of physicochemical and biochemical parameters of grapes and their influence on the composition of volatile impurities of wine materials and young brandy distillates showed high potential of the variety for producing of high-quality brandy products. From the technological point of view, the parameters of low titratable acidity of grapes are problematic because of the reduction of the resistance to microbiological infection and oxidation, and a high level of phenolic composition, which determines the increased level of phenolic substances in wine materials with the oxidation degree. The content of aroma-forming components in wine materials and young brandy distillates is characterized by a higher proportion of higher alcohols than in the initial 'Rkatsiteli' variety, reducing ratio with medium-chain esters and product quality. Technological measures that contribute to reducing the level of phenolic substances in must and wine material and their oxidation degree, as well as the reducing of proportion of higher alcohols and increasing the content of medium-chain esters, are feasible. Studies of the native variety showed the expediency of its use in the technology of single variety for fine brandy production.

\section{Conclusions}

We carried out technological assessment of the native grape variety 'Shabash', studied its physicochemical and biochemical parameters, established the influence on the composition of the aroma-forming complex of wine materials and young brandy distillates. Low titratable acidity, high ability to transfer phenolic substances to the must in grape-crushing, low values of oxidase activity, were highlighted amongst the characteristic properties of grapes. The compositional features of the main volatile elements of brandy wine materials and distillates, characterized by an increased proportion of higher alcohols and decreased content of medium-chain esters, were revealed. High potential of the native variety for the fine brandy production using the technology of single variety was also established. The 
studies conducted are the stage of scientifically substantiated formation of the base of raw materials for brandy production in the Russian Federation.

\section{References}

1. A. Slegers, P. Angers, É. Ouellet, T. Truchon, K. Pedneault, Molecules 20(6), 1098011016 (2015) doi:10.3390/molecules200610980

2. A. Tsakiris, S. Kallithraka, Y. Kourkoutas, J. Sci. Food Agric. 94(3), 404-414 (2014) doi:10.1002/jsfa.6377

3. C. Maria Oliveira, A. César Silva Ferreira, V. De Freitas, A.M.S. Silva, Food Research International 44(5), 1115-1126 (2011) doi:10.1016/j.foodres.2011.03.050

4. C. Puentes, X. Joulia, J.-P. Vidal, M. Esteban-Decloux, Food Bioprod. Process. 112, 31-62 (2018) doi:10.1016/j.fbp.2018.08.010

5. C. López-Vázquez, M. Herminia Bollaín, K. Berstsch, I. Orriolsa, Food Control, 22(11), 1436-1441 (2010) doi:10.1016/j.foodcont.2010.03.008

6. D.E. Urcan, M.-L. Lung, S. Giacosa, F. Torchio, A. Ferrandino, S. Vincenzi, S. Río Segade, N. Pop, L. Rolle, Int. J. Food Prop. 19(1), $76-98$ (2016) doi:10.1080/10942912.2015.1019626

7. I. Lukić, B. Miličević, S. Tomas, S. Radeka, Đ. Peršurić, Journal of the Institute of Brewing 118(3), 285-294 (2012) doi:10.1002/jib.39

8. I. Sen, F. Tokatli, Food Control 46, 446-454 (2014) doi:10.1016/j.foodcont.2014.06.015

9. J. Ledauphin, C. Le Milbeau, D. Barillier, D. Hennequin, J. Agric. Food Chem. 58(13), 7782-7793 (2010) doi:10.1021/jf9045667

10. M.M. Sánchez-Guillén, M. Schwarz-Rodríguez, M.C. Rodríguez-Dodero, M.V. García-Moreno, D.A. Guillén-Sánchez, C. Garcia-Barroso, Food Chem. 286, 275-281 (2019) doi:10.1016/j.foodchem.2019.02.006

11. N.N. Sarvarova, Yu.A. Cherkashina, M.I. Evgen'ev, J. Anal. Chem. 66(12), 11901195 (2011) doi:10.1134/S1061934811120094

12. P. Awad, V. Athès, M. Esteban Decloux, G. Ferrari, G. Snakkers, P. Raguenaud, P. Giampaoli, J. Agri. Food Chem. 65 (35), 7736-7748 (2017) doi:10.1021/acs.jafc.7b02406

13. Q. Sun, M.J. Gates, E.H. Lavin, T. Acree, G.L. Sacks, J. Agric. Food Chem. 59(19), 10657-10664 (2011) doi:10.1021/jf2026204

14. S. Cortés, R. Rodríguez, J. Manuel Salgado, J. Manuel Domínguez, Food Control 22(5), 673-680 (2011) doi:10.1016/j.foodcont.2010.09.006

15. S. Morakul, J.-R. Mouret, P. Nicolle, E. Aguera, J.-M. Sablayrolles, V. Athes, Food and Bioprocess Technology 6(3), 818-827 (2013) doi:10.1007/s1 1947-012-0827-4

16. S. Morakul, J.-R. Mouret, P. Nicolle, I. Cristian Trelea, J.-M. Sablayrolles, V. Athes, Process Biochem. 46(5), 1125-1131 (2011) doi:10.1016/j.procbio.2011.01.034 